\title{
Application potential of high performance steels for weight reduction and efficiency increase in commercial vehicles
}

\author{
Jian Bian · Hardy Mohrbacher · Jian-Su Zhang • \\ Yun-Tang Zhao $\cdot$ Hong-Zhou Lu $\cdot$ Han Dong
}

Received: 6 January 2015 / Accepted: 23 January 2015/Published online: 3 March 2015

(C) The Author(s) 2015. This article is published with open access at Springerlink.com

\begin{abstract}
The fast-growing economy and the gradually established highway system have boosted the road transportation for both passenger and cargo over the last decade in China. From 2000 to 2010 Chinese GDP increased by around $10.15 \%$ annually and the sales of medium and heavy trucks by around $18.87 \%$ (sales increased from 0.2 million in 2000 to 1.3 million in 2010) according to the National Bureau of Statistics of People's Republic of China. Today commercial vehicles consume almost the same amount of fuel as passenger cars in China although the number of commercial vehicles is only about one fourth of passenger cars. It is estimated that around 50\% of imported fuel to China each year will be consumed by vehicle transportation. This situation will worsen fuel shortage problems in the long run and at the same time it is partially responsible for the everworsening air pollution in China. Due to the widespread
\end{abstract}

J. Bian $(\bowtie)$

Niobium Tech Asia, Singapore, Singapore

e-mail: jian.bian@niobiumtech.com

H. Mohrbacher

NiobelCon BVBA, Schilde, Belgium

J.-S. Zhang

Central Research Institute, Baoshan Iron \& Steel Co. Ltd., Shanghai, People's Republic of China

\section{Y.-T. Zhao}

Shougang Research Institute of Technology, Shougang Group, Beijing, People's Republic of China

H.-Z. Lu

Citic Metal Co. Ltd., Beijing, People's Republic of China

H. Dong

Central Iron and Steel Research Institute, Beijing, People's Republic of China overloading in China, lightweight development in commercial vehicles has fallen far behind that of passenger cars with the consequences that Chinese commercial vehicles consume in average about $20 \%$ more fuel, especially the heavy trucks, compared to European models. Under these circumstances it is essential to reduce the vehicle fuel consumption and increase the transport efficiency. The key solution thereby is to implement lightweight design in commercial vehicles as it has been successfully practiced over the last decade in the passenger cars. This paper summarizes highlights given in presentations during the "International seminar on the application of high strength steels in light weight commercial vehicles" with the focus on the development and application of $\mathrm{Nb}$ alloyed high performance steels made for lightweight commercial vehicles.

Keywords Commercial vehicle - Fuel consumption . Light weighting $\cdot$ High performance steel $\cdot \mathrm{Nb}$-based metallurgy

\section{Introduction}

The principle of steel-based light weighting is to replace mild steels by high strength steels and thereby reducing material thickness. The technologies and experiences gained in achieving weight reduction for passenger cars clearly demonstrate that steel remains the most economic and sustainable material for vehicle manufacturing [1]. Thereby Nb-based metallurgy is the most effective way to produce such steels with enhanced performance for lightweight vehicles [2]. Figure 1 shows the weight reduction potential with increasing steel strength in relation to the different loading cases [2]. Over the last decades the steel industry has already developed different kinds of hot-rolled 


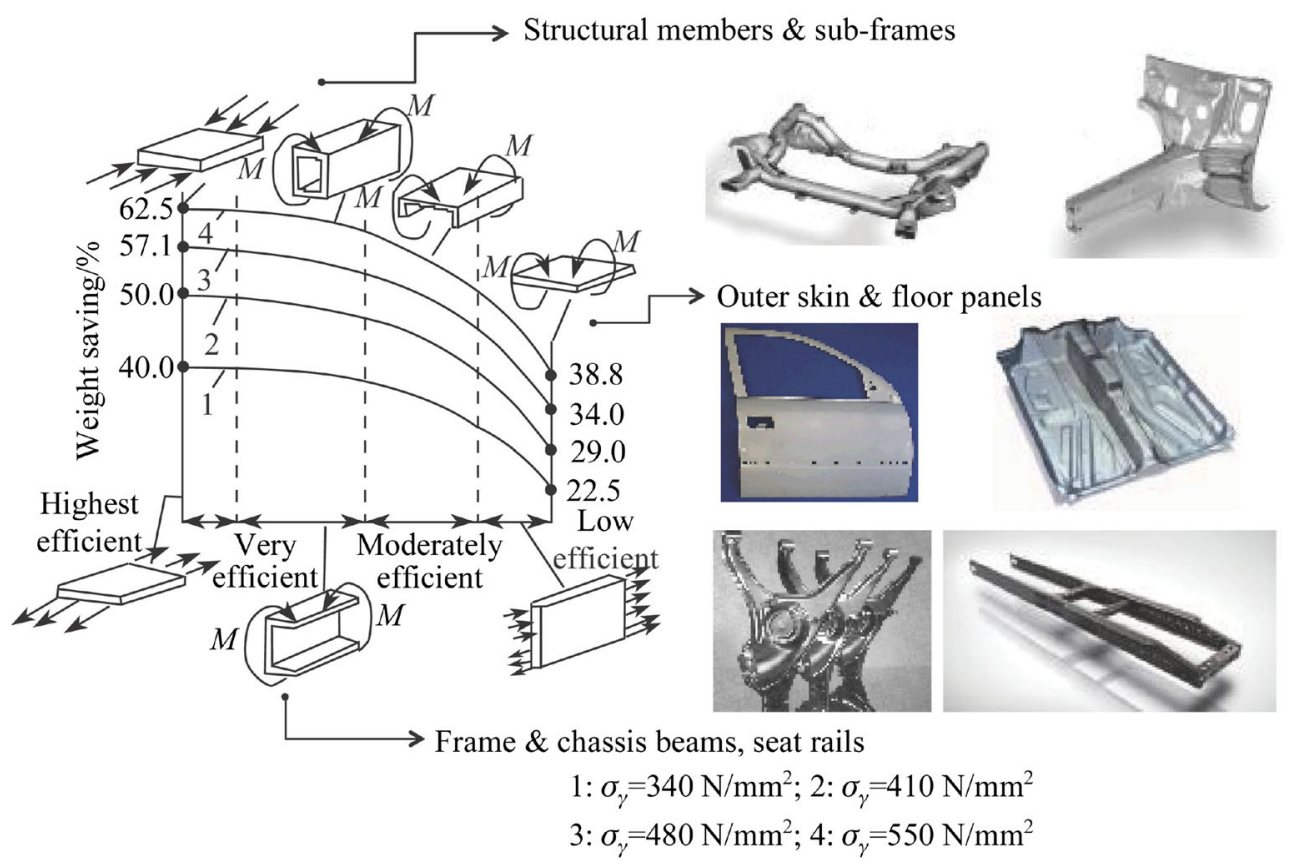

Fig. 1 Weight saving potential by substituting $200 \mathrm{MPa}$ steel with high strength steels

Table 1 Hot-rolled high strength steels for application in the commercial vehicles

\begin{tabular}{|c|c|c|c|c|c|c|c|c|c|}
\hline \multirow{4}{*}{$\begin{array}{l}\text { Grade } \\
\text { Thickness/mm } \\
\text { Width /mm }\end{array}$} & \multicolumn{9}{|c|}{ Micro-alloyed steels(yield strength) } \\
\hline & \multirow{3}{*}{$\begin{array}{l}\mathrm{S} 315 \mathrm{MC} \\
1.5-12.0 \\
75-2000\end{array}$} & $\mathrm{~S} 355 \mathrm{MC}$ & S420MC & S460MC & S500MC & \multirow[t]{3}{*}{ S550MC } & \multirow[t]{3}{*}{ S600MC } & \multirow[t]{3}{*}{ S650MC } & \multirow[t]{3}{*}{ S700MC } \\
\hline & & $1.75-12.0$ & $1.9-12.0$ & $2.0-8.0$ & $2.0-6.5$ & & & & \\
\hline & & $100-1900$ & & & & & & & \\
\hline & \multicolumn{3}{|c|}{ Ferritic-bainitic steels } & \multicolumn{3}{|c|}{ Dual phase steels } & \multicolumn{3}{|c|}{ Martensitic steels } \\
\hline Grade & \multicolumn{2}{|c|}{ FB-W 500} & FB-W 600 & \multicolumn{3}{|c|}{ DP-W600 } & MS-W 100 & & \multirow[t]{3}{*}{ MS-W 1200} \\
\hline Thickness/mm & \multicolumn{2}{|c|}{$1.75-5.5$} & $1.75-4.0$ & & \multicolumn{2}{|l|}{$1.6-5.5$} & \multicolumn{2}{|l|}{$1.5-3.0$} & \\
\hline Width /mm & \multicolumn{2}{|c|}{$100-1900$} & $100-1650$ & & \multicolumn{2}{|l|}{$100-1550$} & \multicolumn{2}{|l|}{$600-1400$} & \\
\hline
\end{tabular}

high strength steels for different applications in commercial vehicles (see Table 1). These high strength steels can be used effectively to substitute the conventional steels in components with the same or even enhanced functionality and simultaneously reduced thickness (see Fig. 2). In the initial phase of developing such high strength steels, carbon was considered to be the most economic and effective element leading to the relative high carbon content in such steels. However the practice has demonstrated that for the automotive application access carbon will deteriorate manufacturing properties like weldability and formability and it will have negative impact on the service performance of the components as well. Nb-based metallurgy provides the optimum solution in this respect due to its two

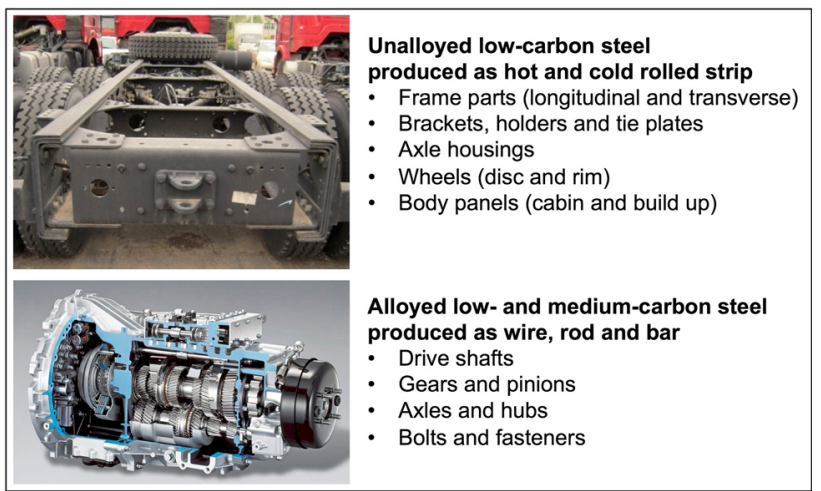

Fig. 2 Major components of commercial vehicles considered for application of high performance steel 
fundamental effects of grain refinement and precipitation hardening [3, 4]. The latest developments and achievements presented at the seminar clearly demonstrated that how $\mathrm{Nb}$ based metallurgy could be adopted to make high performance steels, specifically for commercial vehicles. High performance steels are characterized by enhanced material properties, improved processing behavior and finally better component functionality during service life irrespective of where the material is applied.

\section{Enhanced properties of high performance steel by $\mathrm{Nb}$ microalloying}

With original equipment manufacturers (OEMs) turning towards high strength steels for light weighting, steelmakers are being confronted with challenges of developing high strength steels, which not only meet the specifications in terms of mechanical properties but also suit the manufacturing processes in an established production chain. One of the important aspects to start the manufacturing process with very high strength steel is to have a steel coil with uniform properties and good flatness along the coil. The key solution to achieve uniform properties and good flatness of high strength steel coil is based on an appropriate alloying concept and precise process control. Experience gained at Baoshan Iron \& Steel Co. Ltd. clearly confirmed the advantages of the $\mathrm{Nb}$-based alloy concept in producing the micro-alloyed steel $\mathrm{S} 460 \mathrm{MC}$ compared to the traditional Tibased concept (see Fig. 3). The alloy containing $0.02 \% \mathrm{Nb}$ achieved the same strength level of $460 \mathrm{MPa}$ as the concept using $0.04 \% \mathrm{Ti}$. However the scattering range of strength in the Nb-based concept is less than $50 \mathrm{MPa}$ while for the Tibased concept it is more than $100 \mathrm{MPa}$. The large scattering in the material properties will be presented in the final components made from that steel. On the other hand it

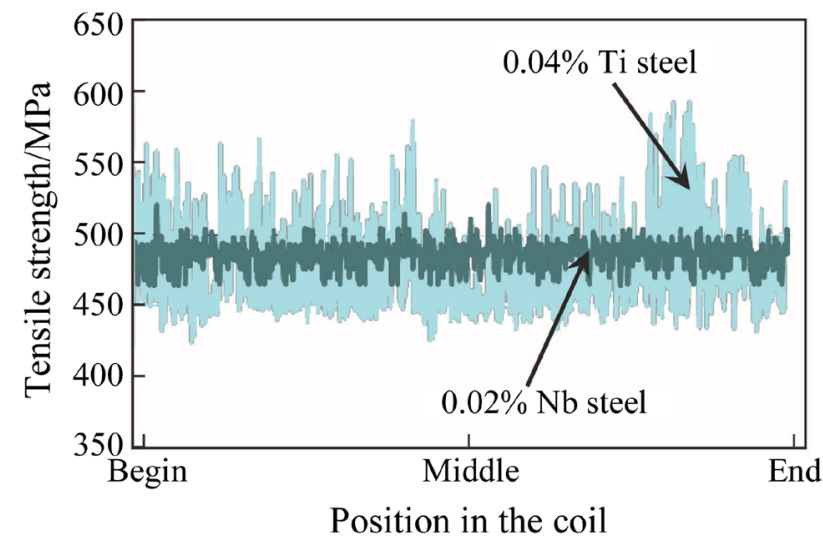

Fig. 3 Scattering of tensile strength in hot-rolled coil of S460MC depending on the applied microalloying concept causes pronounced spring-back effect during the forming process making it more difficult and costly. In China it is quite common to produce micro-alloyed steels by using either Ti-based concepts due to alloying cost or Nb-based concepts. However the $\mathrm{Nb}$ micro-alloyed grades generally achieve much more uniform properties than $\mathrm{Ti}$ grades due to the fact that it is difficult to precisely control the right amount of Ti for precipitation hardening in order to achieve the specified strength because $\mathrm{Ti}$ also forms large precipitates or inclusions with $\mathrm{N}, \mathrm{S}$ and $\mathrm{P}$ at higher temperature. Besides, such large Ti particles are often crack initiators during the forming process (see Fig. 4).

Recently Beijing Shougang Co. Ltd. has developed hotrolled high strength steels with yield strength above $900 \mathrm{MPa}$ for light weighting of commercial vehicle components. The alloying concept is based on low-carbon content and $\mathrm{Nb}-\mathrm{V}-\mathrm{B}$ microalloying processed to a microstructure consisting of bainite or/and martensite. Depending on the thickness and application requirements, thermo-mechanically controlled process (TMCP), TMCP/ tempering or $\mathrm{TMCP} / q u e n c h i n g$ and tempering $(\mathrm{QT})$ process can be applied. Uniform mechanical properties and good toughness in both transverse (trans.) and longitudinal (long.) directions of the coil have been achieved (see Table 2 and Fig. 5). In Table 2, $A$ is total elongation; $r$ is the bending radius; $t$ is the sample thickness.

In order to achieve bainite and martensite in the microstructure of final products based on low-carbon alloy design, high cooling rate in combination with low coiling temperature below bainite or martensite start temperature is required. Due to this reason it is quite challenging to obtain good strip flatness especially with increasing thickness after hot rolling. Increasing the tempering temperature to reduce the residual stress caused by fast cooling or

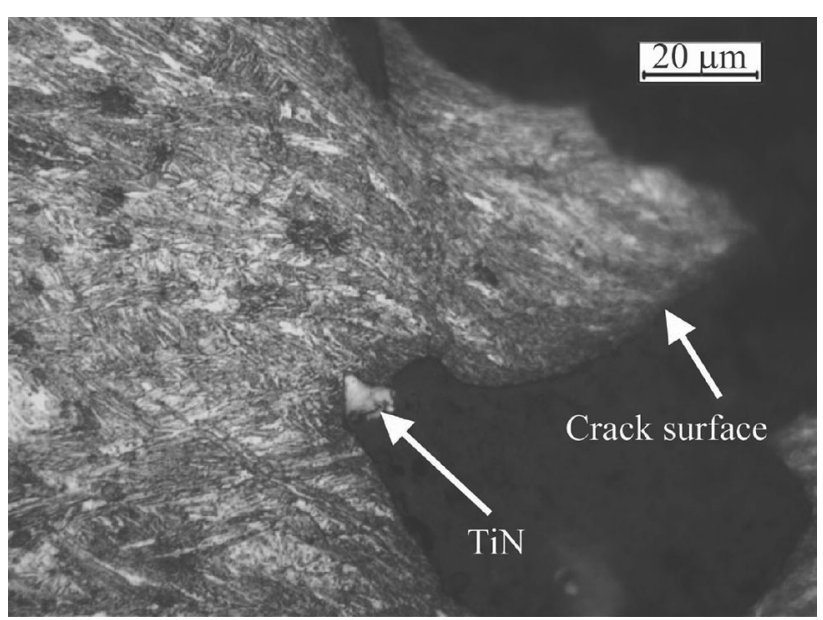

Fig. 4 Component cracking caused by large TiN particles during forming process of Ti micro-alloyed high strength steel 
Table 2 Mechanical properties and toughness of hot-rolled high strength steel for commercial vehicles developed by Beijing Shougang Co. Ltd.

\begin{tabular}{|c|c|c|c|c|c|c|c|c|c|c|c|c|}
\hline \multirow{3}{*}{$\begin{array}{l}\text { Gage } \\
(d) / \\
\mathrm{mm}\end{array}$} & \multirow{3}{*}{$\begin{array}{l}\text { Sample } \\
\text { position }\end{array}$} & \multirow{3}{*}{$\begin{array}{l}\text { Yield } \\
\text { strength / } \\
\mathrm{MPa}\end{array}$} & \multirow{3}{*}{$\begin{array}{l}\text { Tensile } \\
\text { strength / } \\
\mathrm{MPa}\end{array}$} & \multirow[t]{3}{*}{$A / \%$} & \multicolumn{4}{|c|}{ Charpy energy/J } & \multirow{2}{*}{\multicolumn{2}{|c|}{ Bending test }} & \multirow[b]{3}{*}{$\begin{array}{l}\text { Bending } \\
\text { angle } /\left(^{\circ}\right)\end{array}$} & \multirow[b]{3}{*}{$r=4 t$} \\
\hline & & & & & \multicolumn{2}{|c|}{ Temperature $=0{ }^{\circ} \mathrm{C}$} & \multicolumn{2}{|c|}{$\begin{array}{l}\text { Temperature }= \\
-20{ }^{\circ} \mathrm{C}\end{array}$} & & & & \\
\hline & & & & & $\begin{array}{l}\text { Sample } \\
1\end{array}$ & $\begin{array}{l}\text { Sample } \\
2\end{array}$ & $\begin{array}{l}\text { Sample } \\
3\end{array}$ & $\begin{array}{l}\text { Sample } \\
1\end{array}$ & $\begin{array}{l}\text { Sample } \\
2\end{array}$ & $\begin{array}{l}\text { Sample } \\
3\end{array}$ & & \\
\hline \multirow[t]{2}{*}{5.8} & Trans. & 944 & 1066 & 12.8 & 65 & 67 & 64 & - & - & - & $90^{\circ}$ & Ok \\
\hline & Long. & 946 & 1059 & 14.2 & - & - & - & 52 & 54 & 53 & $90^{\circ}$ & Ok \\
\hline
\end{tabular}

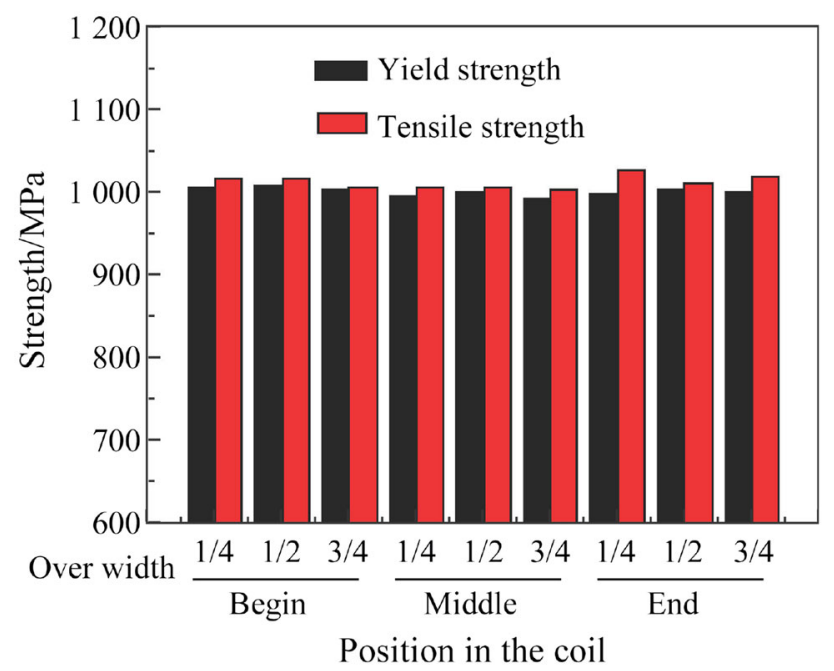

Fig. 5 Uniformity of strength in hot-rolled coil with yield strength above $900 \mathrm{MPa}$ produced by Beijing Shougang Co. Ltd. $(d=5 \mathrm{~mm})$

different phase transformations over the thickness solved this problem. The strength loss caused by the tempering effect on the bainitic and/or martensitic microstructure was compensated by increasing the $\mathrm{Nb}$ and $\mathrm{V}$ content in the steel providing additional precipitation strengthening. Through the alloy modification and process optimization, hot-rolled high strength steel with yield strength above $900 \mathrm{MPa}$ can be produced showing very good flatness (see Table 3). Besides, low-carbon content and a favorable microstructure provide good weldability, toughness and formability.

This newly developed steel has been successfully applied in dump trucks, semi-trailers and mobile cranes reducing the vehicle weight. For instance in a new semitrailer design (see Fig. 6) steel with 900 MPa yield strength was used to replace Q345 reducing the weight of the longitudinal beams with $60 \%$. It was also applied in structural parts and walls of the truck body. Together with other lightweight design solutions in the suspension and wheels the total dead weight of the vehicle was reduced down to $4.9 \mathrm{t}$ which was $40 \%$ less compared to the previous model. Up to now, two pilot vehicles have passed $180000 \mathrm{~km}$ road testing. Fuel saving has amounted to 0.245 Yuan $/ \mathrm{km}$ and 44000 Yuan/year. Besides, the transport revenue increases by 9000 Yuan/year when the payload is increased by $2 \mathrm{t}$ per trip. Accordingly, such ultra high strength steel brings benefits to the entire supply chain ranging from steelmaker to the end-user.

Special steels are widely used in the commercial vehicles, for example, in the power train and suspension area. The quality of special steels is one of the most important factors with regard to durability and performance of the vehicle. Micro-alloyed special steels and particularly casecarburizing steels can achieve higher load bearing capacity and improve the total performance. In this context two new alloying designs with $\mathrm{Nb}$ microalloying have been investigated to improve the high-end case-carburizing steel grade $18 \mathrm{CrNiMo} 7-6$ which is being standardly used for making high performance gear [5] (see Table 4).

One of the new alloy designs is aiming for higher performance with regard to future requirements on mediumsized and large-sized transmissions. Mn and Mo are increased for a better hardenability while $\mathrm{Ni}$ is reduced for cost reduction. Besides, a high Ni content can stabilize retained austenite in the case layer reducing its hardness. $\mathrm{Nb}$ microalloying is applied to restrict austenite grain coarsening during the carburizing process. Accordingly higher carburizing temperature can be applied to shorten the processing time and lower production cost. Furthermore, grain refinement results in higher toughness and fatigue strength. Besides providing fine grain size, appropriate microalloying in carburizing steel also reduces grain size scattering. This limits the distortion upon quenching and hence reduces hard machining efforts. The other new alloy design is aiming for lower total alloy cost due to significant reduction of the $\mathrm{Ni}$ alloy content, yet achieving similar performance as the reference grade 18CrNiMo7-6. Nb microalloying is applied for the same reasons as mentioned in the other new alloy design. The achieved mechanical properties of both newly designed case-carburizing steels indeed correspond to the postulated expectations (see Table 5).

As expected concept $V_{1}$ achieves much higher strength due to improved hardenability and at the same time results in a higher rotating fatigue limit due to grain refinement. 
Table 3 Shape deviation after blanking of hot-rolled DQ steel $(d=5 \mathrm{~mm})$ with yield strength above $900 \mathrm{MPa}$ (steel produced by Beijing Shougang Co. Ltd.)

\begin{tabular}{llll}
\hline $\begin{array}{l}\text { Blanking length/ } \\
\mathrm{mm}\end{array}$ & $\begin{array}{l}\text { Flatness deviation in rolling direction/ } \\
\mathrm{mm}\end{array}$ & $\begin{array}{l}\text { Flatness deviation in transverse direction/ } \\
\mathrm{mm}\end{array}$ & $\begin{array}{l}\text { Straightness after } \\
\text { blanking }\end{array}$ \\
\hline 6000 & 0.1 & 0.2 & $<1 \mathrm{~mm} / 1000 \mathrm{~mm}$ \\
\hline
\end{tabular}

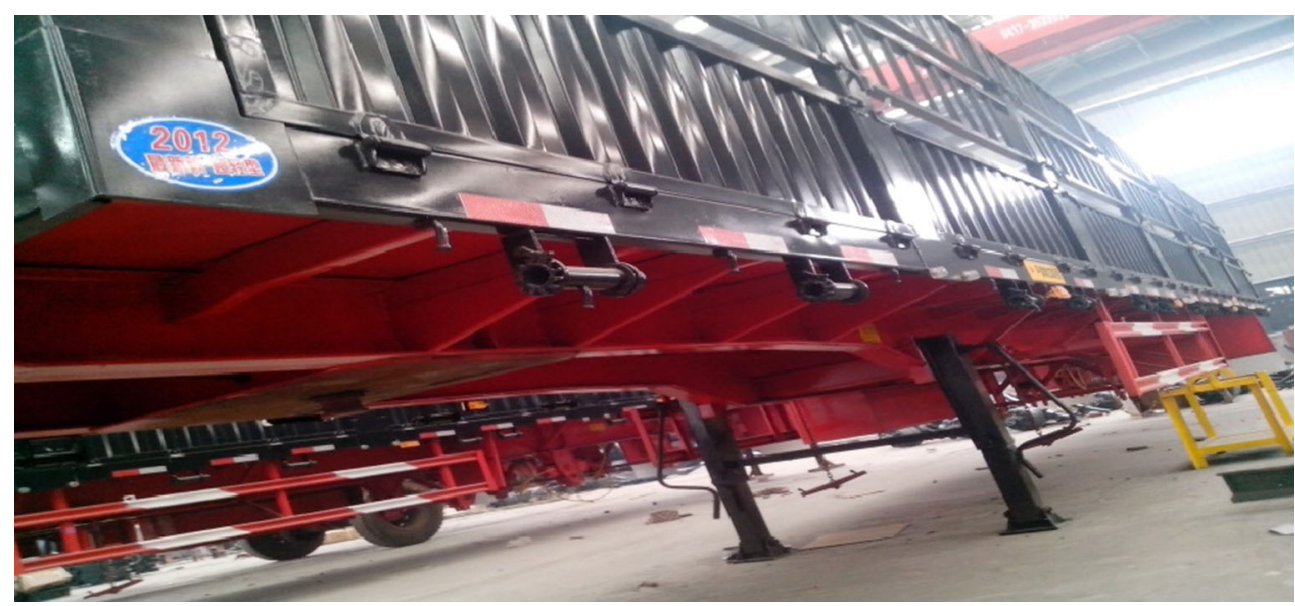

Fig. 6 Lightweight semi-trailer made in China by high strength steels with yield strength above $900 \mathrm{MPa}$

Table 4 Chemical composition of $\mathrm{Nb}$ micro-alloyed case-hardening steels in comparison with standard $18 \mathrm{CrNiMo7-6}$

\begin{tabular}{llllllll}
\hline Steel grade & $w(\mathrm{C}) / \%$ & $w(\mathrm{Si}) / \%$ & $w(\mathrm{Mn}) / \%$ & $w(\mathrm{Cr}) / \%$ & $w(\mathrm{Mo}) / \%$ & $w(\mathrm{Ni}) / \%$ & $w(\mathrm{Nb}) / \%$ \\
\hline Concept $\mathrm{V}_{1}$ & 0.26 & 0.12 & 1.46 & 1.23 & 0.54 & 0.91 & 0.03 \\
Concept $\mathrm{V}_{2}$ & 0.21 & 0.25 & 1.17 & 1.15 & 0.21 & 0.22 \\
18 CrNiMo7-6 (1.6587) & $0.15-0.21$ & $\leq 0.40$ & $0.50-0.90$ & $1.50-1.80$ & $0.25-0.35$ & $1.40-1.70$ \\
\hline
\end{tabular}

Table 5 Mechanical properties of Nb micro-alloyed case-carburizing steels in comparison with $18 \mathrm{CrNiMo} 7-6$ (hardened at $880{ }^{\circ} \mathrm{C} / 2 \mathrm{~h}+$ oil $/$ $\left.180{ }^{\circ} \mathrm{C} / 2 \mathrm{~h}\right)$

\begin{tabular}{lcrr}
\hline Property & Concept $\mathrm{V}_{1}$ & Concept $_{2}$ & $18 \mathrm{CrNiMo7-6}$ \\
\hline Tensile stregth/MPa & 1758 & 1182 & 1182 \\
Impact energy/J & 47 & 55 & 80 \\
Rotating fatigue limit $\sigma_{(50 \%)} @ N=10^{7} \mathrm{MPa}$ & 722 & 491 & 510 \\
Hardenability@11 mm /HRC & 51 & 44 & 41 \\
Hardenability@25 mm /HRC & 50 & 36 & 36 \\
\hline
\end{tabular}

The toughness remains at a good level in spite of the high tensile strength. Concept $\mathrm{V}_{2}$ with reduced total alloy cost achieves similar properties compared to 18CrNiMo7-6. Toughness is reduced due to the much-reduced Ni content but still remains on an acceptable level. Gears made from both innovative case-carburizing steels have been benchmarked by running performance tests. In these tests gear tooth root fatigue and gear tooth flank micro-pitting were characterized as performance criteria. Concept $V_{1}$ is clearly outperforming existing case-carburizing grades (framed area in Figs. 7 and 8). Alloy concept $V_{2}$ matches the performance spectra of existing case-carburizing grades despite its reduced alloy cost (see Figs. 7 and 8). In Figs. 7 and 8, Grade ML stands for the minimum requirement; grade MQ represents requirements which can be met by experienced manufacturers at moderate cost; grade $\mathrm{ME}$ represents requirements which must be realized when higher allowable stresses are desirable. 


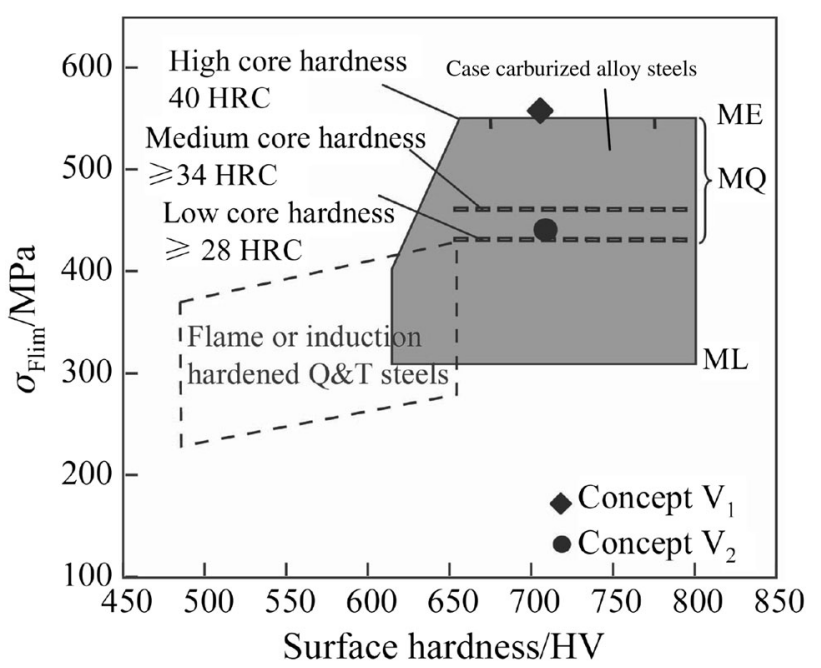

Fig. 7 Benchmarking of gear tooth root fatigue of innovative casecarburizing steels compared to the conventional alloys

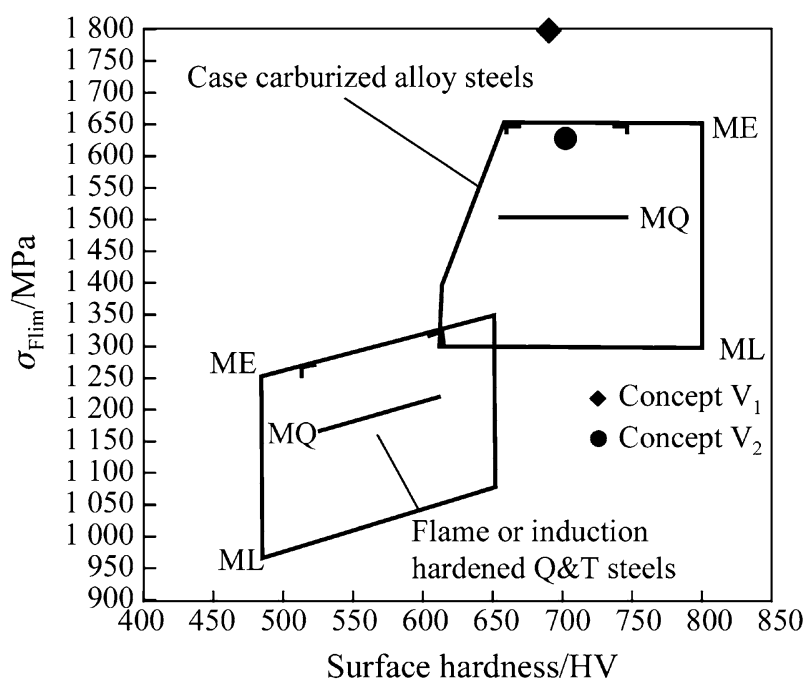

Fig. 8 Benchmarking of gear tooth flank micro-pitting of innovative case-carburizing steels compared to the conventional alloys

Pistons for truck engines are another example for the application of $\mathrm{Nb}$ micro-alloyed special steels. In the diesel engine of modern trucks, the operating temperature can reach up to $650{ }^{\circ} \mathrm{C}$ and the operating pressure up to $20 \mathrm{MPa}$. Due to this reason steel grade $42 \mathrm{CrMo}$ started being used recently to replace Al-made pistons. But surface oxidation and material softening reduce the performance of the steel due to high operating temperature. The modified steel grade
42SiCrMo with $\mathrm{Nb}$ microalloying (see Table 6) reduces scale forming by a factor of 10 compared to the standard grade $42 \mathrm{CrMo}$ under the same operating conditions [6]. Due to the synergy between $\mathrm{Nb}$ and Mo in such steel complex precipitates of $\mathrm{Nb}(\mathrm{Mo}) \mathrm{C}$-type are much finer and more resistant to particle coarsening during high operating temperature. Accordingly the steel has 20\% higher tensile strength and it is simultaneously more resistant to softening when exposed to high temperature.

\section{Improved processing properties of high strength steels by Nb microalloying}

The formability and weldability of steel need to be specifically considered with increasing strength. Both properties which are directly related to vehicle manufacturing have considerable impact on processing feasibility. Material failure occurring during welding or forming will reduce the production efficiency and consequently increase the production costs. Generally it is important to reduce the steel's carbon equivalent for good weldability. Increased carbon content in combination with low heat input causes high hardness in the heat-affected zone (HAZ) with the risk of cold cracking. Steel based on low-carbon content and $\mathrm{Nb}$ microalloying can effectively provide high strength and good weldability. Both hardness and toughness in the HAZ depend much on the heat input and cooling rate of the applied welding process. For a good combination of both properties it is important to define a process window in terms of heat input and cooling rate in order to limit the maximum hardness to below $350 \mathrm{HV}$ and the transition temperature to below $-40{ }^{\circ} \mathrm{C}$. A narrow process window is related to poor weldability from the material side and difficult weld processing from manufacturing side. Reducing the carbon content from $0.08 \%$ to $0.03 \%$ and increasing $\mathrm{Nb}$ content from $0.06 \%$ to $0.09 \%$ in an innovative alloy concept for steel grade S500MC [7], the HAZ hardness could be significantly reduced over the entire range of heat input experienced by typical assembly welding processes (see Fig. 9). Such an alloying concept also allows a larger process window in terms of cooling rate after welding avoiding cold cracking and generally providing good toughness in the HAZ (see Fig. 10). For the steel grades S-MC up to $900 \mathrm{MPa}$ yield strength, no preheating is required for the welding process if the heat input is adjusted within a reasonable range.

Table 6 Modified steel grade with Nb microalloying for the application of engine pistons in the tuck diesel engines for the high operating temperature and pressure

\begin{tabular}{lllllllll}
\hline Steel grade & $w(\mathrm{C}) / \%$ & $w(\mathrm{Si}) / \%$ & $w(\mathrm{Mn}) / \%$ & $w(\mathrm{Cr}) / \%$ & $w(\mathrm{Mo}) / \%$ & $w(\mathrm{Cu}) / \%$ & $w(\mathrm{Nb}) / \%$ & $w(\mathrm{Ti}) / \%$ \\
\hline 42SiCrMo modified & $0.40-0.43$ & $2.0-3.0$ & $0.70-0.85$ & $0.90-1.15$ & $0.15-0.25$ & 0.25 & 0.04 & 0.02 \\
\hline
\end{tabular}




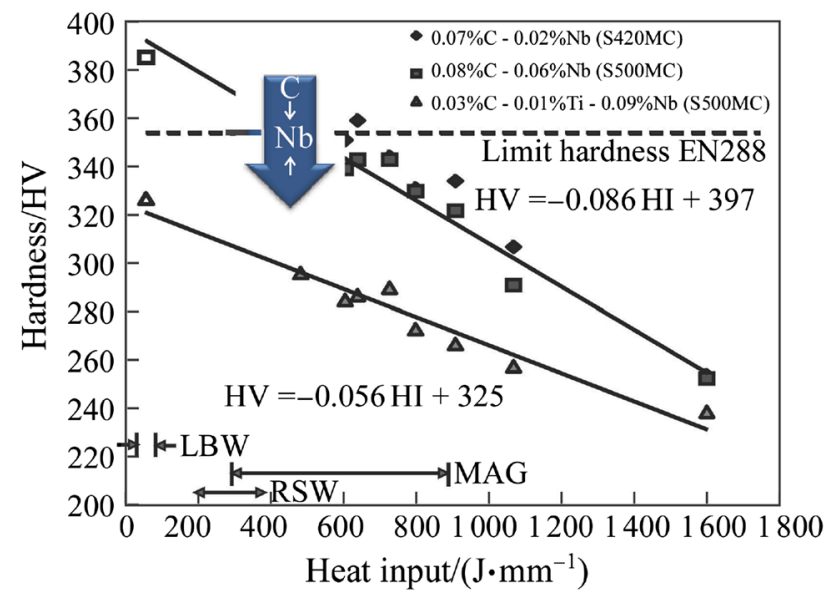

Fig. 9 Effect of heat input on peak hardness in the HAZ for various Nb-based alloy concepts of steel grade S500MC (LBW: laser beam welding, RSW: resistance spot welding, MAG: metal active gas welding)

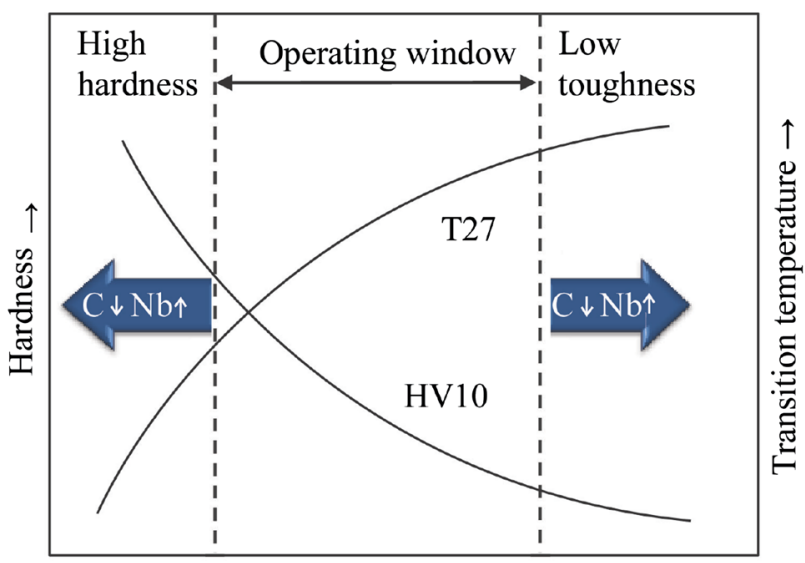

Cooling time $t 8 / 5 \rightarrow$

Fig. 10 Schematic influence of alloying strategies and cooling rate (heat input) on the operating window in terms of HAZ hardness and toughness

In many cases, modern high strength steels consist of a multiphase microstructure using the strengthening mechanism of transformation which is hardened to obtain hard phases like bainite, martensite and retained austenite embedded in a ductile phase such as ferrite. For such multiphase steels $\mathrm{Nb}$ microalloying has been increasingly applied to improve the homogeneity of the microstructure through grain refinement [8]. With reduced grain size, the banding structure of hard phases like martensite can be suppressed and the distribution of different phases is more homogeneous [9]. Besides, the hardness difference between hard and soft phases is being reduced, because $\mathrm{Nb}$ microalloying has a more profound strengthening effect on ferrite than the other hard phases like bainite and martensite. Such improvement in the microstructural details directly

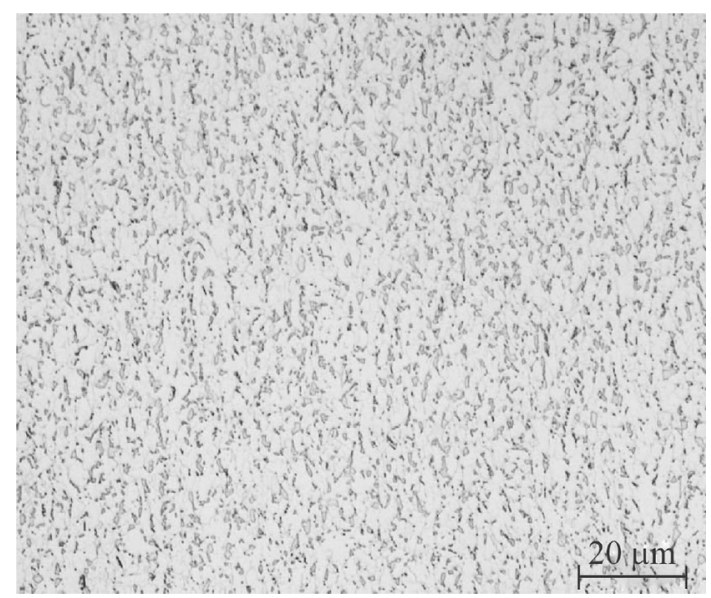

Fig. 11 Microstructure of hot-rolled FB600 steel developed by Benxi Iron \& Steel Group Co. Ltd. for wheel rim application

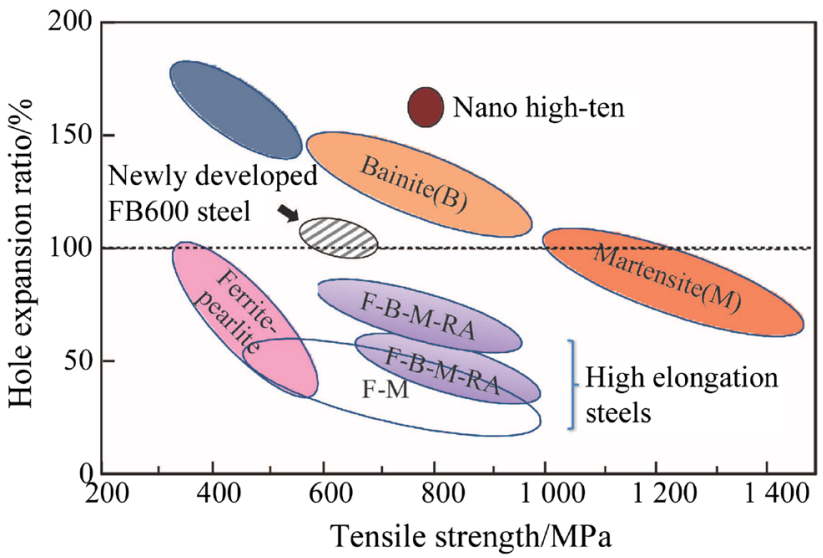

Fig. 12 Hole expansion ratio of newly developed hot-rolled FB600 compared to other commonly used automotive steel grades

leads to an improved forming behavior of the steel, especially during bending and hole expansion operations. Particularly these properties are important for the manufacturing of truck frames, structural reinforcements and wheels. This also reduces the sensitivity to the edge cracking of high strength steels during the forming process. Benxi Iron \& Steel Group Co. Ltd. recently developed the hot-rolled ferritic-bainitic grade FB600 based on a lowcarbon content and $\mathrm{Nb}$ microalloying for the application in lightweight wheels. Very fine and homogeneous microstructure consisting of ferrite $(60 \%-70 \%)$ and bainite $(30 \%-40 \%)$ is achieved. Thereby the ferrite grain size is as small as ASTM 13 (see Fig. 11). Apart from good mechanical properties (elongation above $30 \%$ with tensile strength beyond $600 \mathrm{MPa}$ ), this newly developed FB600 demonstrates excellent hole expansion properties of more than $100 \%$ (see Fig. 12) outperforming all existing DP steels. Due to such excellent properties this hot-rolled FB600 in gage of $4.5 \mathrm{~mm}$ has been applied for 
manufacturing wheel rims helping to reduce the rim weight from $13.8 \mathrm{~kg}$ to $11.5 \mathrm{~kg}$ corresponding to a $16.7 \%$ weight reduction from the original wheel rim. Through precise control of inclusions and grain refinement, the customer fatigue requirements have been satisfied by reaching 1.1 million revolutions in a radial fatigue test.

\section{Improving component functionality and service life by $\mathrm{Nb}$ microalloying}

$\mathrm{Nb}$ microalloying has been increasingly used in the high strength steels to improve the service performance of components in passenger cars as well as commercial vehicles. For instance in press hardening (hot forming) steels, $\mathrm{Nb}$ microalloying can improve the toughness through grain refinement so that press hardened components will expose better crash behavior with higher energy absorption especially when the crash occurs in a low temperature environment. Another concern of OEMs is the delayed cracking induced by hydrogen embrittlement which can dramatically reduce the crash performance of press hardened components due to severe degradation of strength and toughness. Investigations revealed that $\mathrm{Nb}$ precipitates dispersed in the martensitic matrix had the ability of trapping hydrogen present in the steel and made it less diffusible. Thus it will less segregate to grain boundaries causing the typical intergranular fracture or material defects like large inclusions and microcracks which lead to local damage. This perception leads to the development of $\mathrm{Nb}$ alloyed press hardening steel. Adding $0.05 \% \mathrm{Nb}$ to press hardening steel based on the alloy concept $22 \mathrm{MnB} 5$ resulted in more than three times higher critical fracture stress compared to the conventional steel under the same hydrogen charging conditions (see Fig. 13). It also lowered the ductile-to-brittle transition temperature thus leading to better low temperature toughness. Today press-hardening steel has become state of the art technology in car body engineering for passenger cars. Press hardening steel represents as much as $38 \%$ of the total body weight of the recent sports utility vehicle (SUV) model Volvo XC90 [10]. There is a clear trend to use press hardening steel (PHS) in the commercial vehicles for reducing weight and simultaneously increasing safety. This approach has been already implemented in light commercial vehicles, e.g., Ford Transit [11] as well as in full-size trucks, e.g., Scania.

Approximately 4000 to 7500 joining bolts are used for the assembly of commercial vehicles adding about $50-90 \mathrm{~kg}$ to the total weight of the vehicle. In conventional Chinese truck manufacturing 10.9 grade high strength bolts are used in the engine block and 8.8 grade for other applications. Replacing 10.9 grade bolts by ultrahigh strength bolts, such as 13.9 grade, $10 \%$ reduction

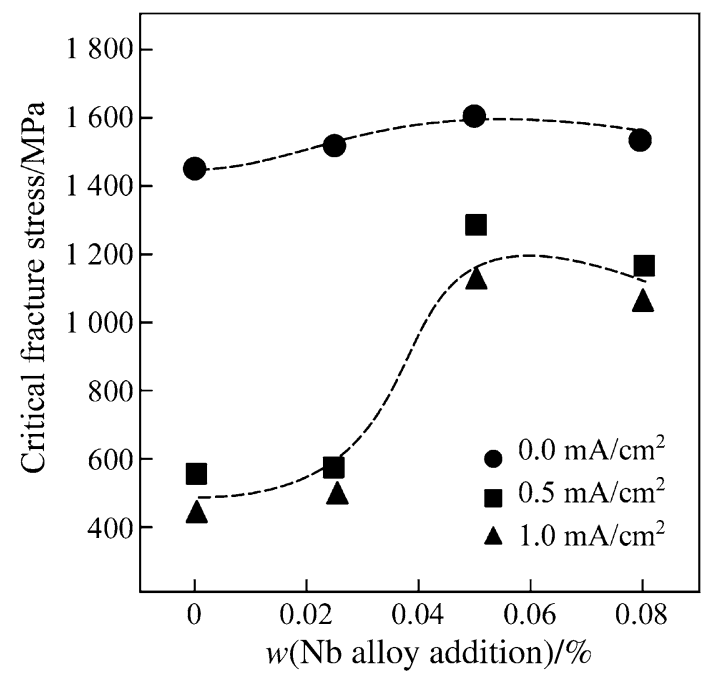

Fig. 13 Effect of $\mathrm{Nb}$ microalloying on the critical fracture stress of press hardening steel based on 22MnB5 under the same hydrogen charging conditions

of the joining bolt weight can be achieved while the strength is increased by $30 \%$. However the major obstacle in using ultrahigh strength bolts is hydrogen induced cracking. Steel grade $42 \mathrm{CrMo}$ has been widely used in China for making high strength bolts. However the resistance to hydrogen induced cracking of this alloy is insufficient for the application. Modification of this steel grade by microalloying allows tolerating up to six times higher hydrogen content without causing severe hydrogen embrittlement. This is due to the hydrogen trapping effect of microalloy precipitates (see Fig. 14) [12]. With increasing tempering temperature, the amount of microalloy precipitates increases and so does the hydrogen trapping potential. However the hydrogen trapping effect decreases again when the tempering temperature becomes too high as this leads to precipitate coarsening by the so-called Ostwald ripening mechanism. Hydrogen testing under the identical conditions revealed that the conventional grade $42 \mathrm{CrMo}$ showed the typical intergranular fracture due to severe hydrogen embrittlement at lower hydrogen content. On the contrary, micro-alloyed grade $42 \mathrm{CrMo}$ exposed transgranular fracture at six times higher hydrogen content (see Fig. 15). Transgranular fracture generally occurs at a higher critical fracture stress than intergranular fracture. Microalloy and appropriate precipitate dispersion being a metallurgical remedy against hydrogen embrittlement lead to the development of steel grades for ultrahigh strength bolts in China. These have not only higher strength but also higher resistance to fatigue as well as to hydrogeninduced cracking (see Fig. 16). More than one million ultrahigh strength bolts made from steel grade 13.9 have already been used for different applications in China. Through the improvement of material properties, the 


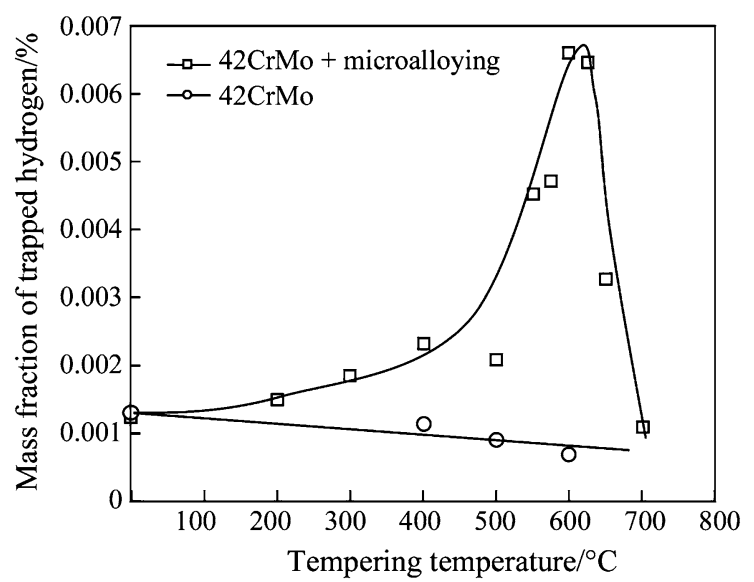

Fig. 14 Impact of microalloying on the hydrogen trapping effect of high strength bolts made from $42 \mathrm{CrMo}$ and tempered at different temperatures

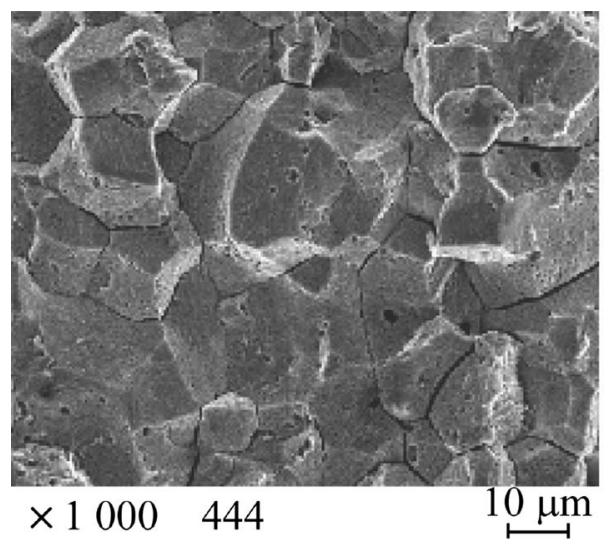

(a) 42CrMo intergranular fracture

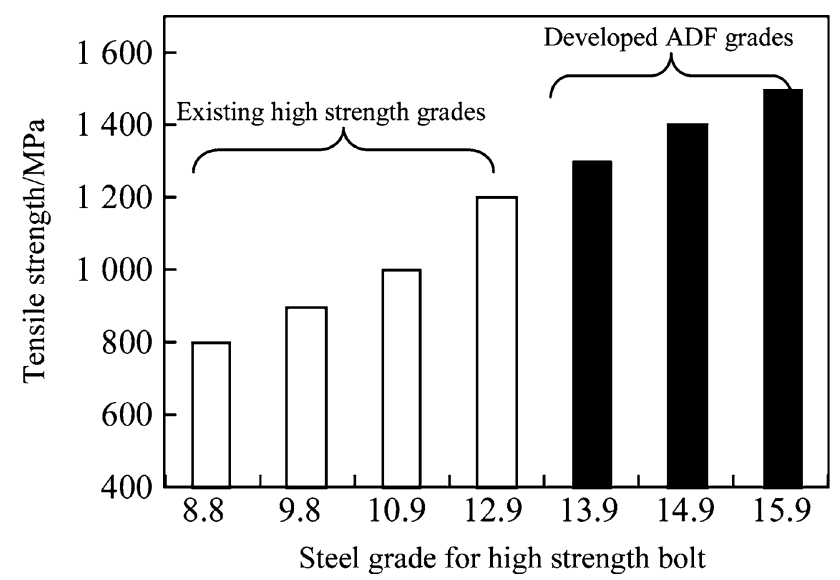

Fig. 16 Tensile strength of steel grades for high strength bolts developed in China

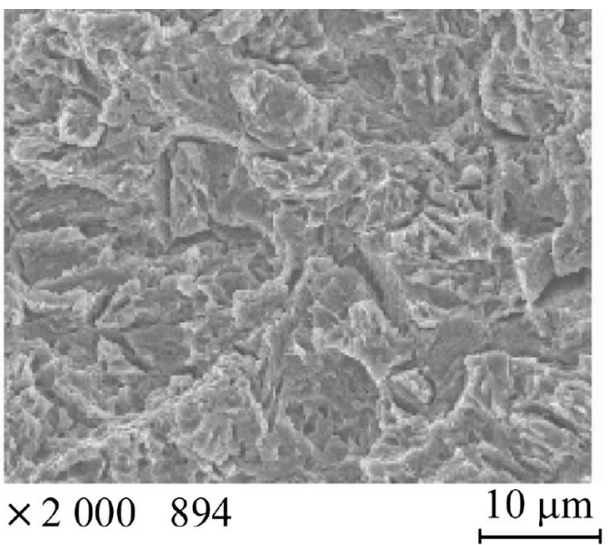

(b) $42 \mathrm{CrMo}+$ microalloying transgranular fracture

Fig. 15 Effect of microalloying on the fracture appearance of high strength bolts made from grade 42CrMo after exposure to identical hydrogen charging conditions

functionality of the joining bolts and the safety of the vehicles have been significantly enhanced. It is noteworthy in this context that $60 \%-70 \%$ of the accidents caused by commercial vehicles in China are related to the broken joining bolts.

\section{Conclusions}

Due to pressing sustainability issues such as fuel consumption and air pollution in China, it is indispensible to increase the transport efficiency by reducing the weight of commercial vehicles thus increasing payload capacity. The key approach of implementing lightweight design in commercial vehicles is to use high performance steel for manufacturing major components. The technologies and experiences gained in achieving weight reduction in passenger cars clearly confirm this approach and they are readily available in China to be transferred to commercial vehicles.

Lightweight design with steel is economical as it even often results in reduced cost. The weight reduction and hence lower consumption of material to manufacture components usually compensate the moderate price increase for high performance steel. Producing less but more profitable high performance steel is beneficial for the Chinese steel industry as well as for the environment in general. Regarding life cycle assessment steel has globally a better total emission balance than competing materials available for weight reduction. 
Nb-based metallurgy has proven to be particularly beneficial when producing high performance steels for commercial vehicle applications. Such $\mathrm{Nb}$ micro-alloyed steels have superior properties with regard to manufacturing and also reveal better durability during the vehicle operation phase.

Open Access This article is distributed under the terms of the Creative Commons Attribution License which permits any use, distribution, and reproduction in any medium, provided the original author(s) and the source are credited.

\section{References}

1. Presentation by Mercedes-Benz at the 16th global car body benchmarking conference 2014, Automotive Circle International, Bad Nauheim, Germany

2. Mohrbacher H (2013) Reverse metallurgical engineering towards sustainable manufacturing of vehicles using $\mathrm{Nb}$ and Mo alloyed high performance steels. Adv Manuf 1(1):28-41

3. Morrison WB (2009) Microalloy steels-the beginning. Mater Sci Technol 25(9):1066-1073

4. Altuna MA, Iza-Mendia A, Gutiérrez I (2012) Precipitation of Nb in ferrite after austenite conditioning. Part II: strengthening contribution in high-strength low-alloy (HSLA) steels. Metal Mater Trans A 43(12):4571-4586
5. Hippenstiel F, Mohrbacher H (2011) Optimization of molybdenum alloyed carburizing steels by $\mathrm{Nb}$ microalloying for large gear applications. In: Materials science and technology (MS\&T) conference \& exhibition, Columbus, OH, 16-20 October, 2011

6. Elvira R, Schwarz O, Schmitz EP et al (2014) New steel engine components with superior strength and oxidation resistance at high temperatures. In: Steels in cars and trucks (SCT), Braunschweig, 15-19 June, 2014

7. Haensch W, Klinkenberg C (2005) Low carbon niobium alloyed high strength steel for automotive hot strip. Ironmaking \& Steelmaking 32(4):342-346

8. Mohrbacher H (2013) Advanced metallurgical concepts for DP steels with improved formability and damage resistance. In: Proceedings of the international symposium on new developments in advanced high-strength sheet steels, Vail, AIST 2013

9. Hebesberger T, Pichler A, Pauli H (2008) Dual-phase and complexphase steels: AHSS material for a wide range of applications. In: Proceedings of steels in cars and trucks, Wiesbaden, June, 2008

10. Presentation by Volvo at the 16th Global car body benchmarking conference 2014, Automotive Circle International, Bad Nauheim, Germany

11. Presentation by Ford at the 15 th global car body benchmarking conference 2013, Automotive Circle International, Bad Nauheim, Germany

12. Wei FG, Hara $T$, Tsuchida $T$ et al (2003) Hydrogen trapping in quenched and tempered $0.42 \mathrm{C}-0.30 \mathrm{Ti}$ steel containing bimodally dispersed TiC particles. ISIJ international 43(4):539-547 